\title{
Primary Clear Cell Renal Cell Carcinoma with Marked Intraluminal Mucin Secretion
}

\author{
Oğuzhan OKCU', Kemal BEHZATOĞLU', Yasemin ÇAKIR', Esra PAŞAOĞLU², Uğur YÜCETAŞ \\ Department of Pathology, 'Istanbul Education and Research Hospital, iSTANBUL, TURKEY, ${ }^{2}$ Bagcilar Education and Research Hospital, ISTANBUL, TURKEY, \\ ${ }^{3}$ Department of Urology, Istanbul Education and Research Hospital, ISTANBUL, TURKEY
}

\begin{abstract}
Clear cell renal cell carcinoma with mucin secretion is an unexpected situation. Primary renal adenocarcinoma and various metastatic carcinomas should be considered in the differential diagnosis. Prognostic significance is not yet fully known due to the limited number of reported cases, and these lesions have been grouped under unclassified renal cell carcinoma. In our study, clear cell renal cell carcinoma with significant luminal mucin secretion is discussed with its histological, histochemical and immunohistochemical features.
\end{abstract}

Key Words: Clear cell renal cell carcinoma, Mucin

\section{INTRODUCTION}

Mucins are complex carbohydrates secreted by epithelial and connective tissues. They are secreted by normal cells of endodermal origin such as gastric, intestinal, pancreatic, prostatic and pulmonary cells (1-3). Mucin secretion increasesin adenocarcinomas of these organs, and sometimes gastrointestinal system and breast adenocarcinomas can be named "mucinous adenocarcinoma' when there is excessive extracellular mucin secretion. The presence of mucin in the gland is also a feature supporting the diagnosis of prostate carcinoma. Similarly, it is important to determine mucin secretion in the diagnosis and differential diagnosis of adenocarcinoma metastases from this organ. Mucin presence in the gland is an unexpected feature and very rare in renal cell carcinomas and especially in the common clear cell type. Only two cases have been reported in the English literature so far $(4,5)$.

Renal adult tumors that show significant extracellular mucin production are mucinous tubular and spindle cell carcinoma, oncocytoma, tubulo-papillary adenoma, collecting duct carcinoma, papillary renal cell carcinoma (RCC), tubulocystic carcinoma, and renal medullary carcinoma $(4,6)$. However, extracellular (intraluminal) mucin expression is quite rare in clear cell RCC. RCC is therefore not considered in the presence of intraluminal mucin in metastatic carcinomas of unknown origin. Clear cell RCC's with mucin secretion have not been defined in the most recent Vancouver classification and are generally evaluated within the unclassified RCC classification (7).

(Turk Patoloji Derg 2019, 35:52-54)

Received : 18.05.2016 Accepted : 14.07.2016
We discuss the histological, histochemical and immunohistochemical features and the problems related to differential diagnosis presented by a conventional renal cell carcinoma case with extensive luminal mucin secretion.

\section{CASE REPORT}

A 71-year-old male with no symptoms was incidentally found to have a $5 \mathrm{~cm}$ mass in the right kidney upper pole with abdominal ultrasonography during a routine examination (check-up). CT imaging showed no evidence of abdominal or retroperitoneal lymphadenopathy, organomegaly or distant metastasis. Right radical nephrectomy was therefore performed by the urology department.

On macroscopic evaluation, there was a nodular, welldelineated tumoral lesion $5 \mathrm{~cm}$ in size, located in the upper pole of the nephrectomy material measuring $11 \times 8 \times 5 \mathrm{~cm}$. The tumor was yellow-brown, while occasional areas had a more shiny appearance. Hemorrhage in focal areas was also observed. The tumor infiltrated the hilus fatty tissue.

Microscopic evaluation revealed that the tumor contained alveolar nests containing cells with a clear cytoplasm, prominent cytoplasmic borders and a glandular pattern. The nuclei in these clear cell areas had features of Fuhrman grade II. The cytoplasm was eosinophilic-granular and the nuclei were slightly larger in some areas (Fuhrman grade III). There was a definite distinction between the areas with a granular cytoplasm and clear cytoplasm (Figure 1). The most interesting feature of the areas with a granular cytoplasm was the blue-colored mucin-like material filling the gland lumens (Figure 2,3).

Correspondence: Oğuzhan OKCU

İstanbul Eğitim ve Araştırma Hastanesi, Patoloji Laboratuvarı,

İSTANBUL, TURKEY

E-mail: oguzhanokcu@hotmail.com Phone: +90 5432731968 
The mucin-like material stained dark rose with mucicarmen and blue with PAS-Alcian blue (Figure 4) $\mathrm{pH} 2.5$, while intracytoplasmic staining was only observed in a few cells on histochemical staining.

Immunohistochemical studies revealed that all cells with clear and granular cytoplasm were positive for PAX-8 and CD10 but negative for vimentin and cytokeratin (CK) 7. The case was diagnosed as "clear renal cell carcinoma with marked intraluminal mucin secretion". The patient is alive after 74 months of follow-up without any evidence of recurrence.

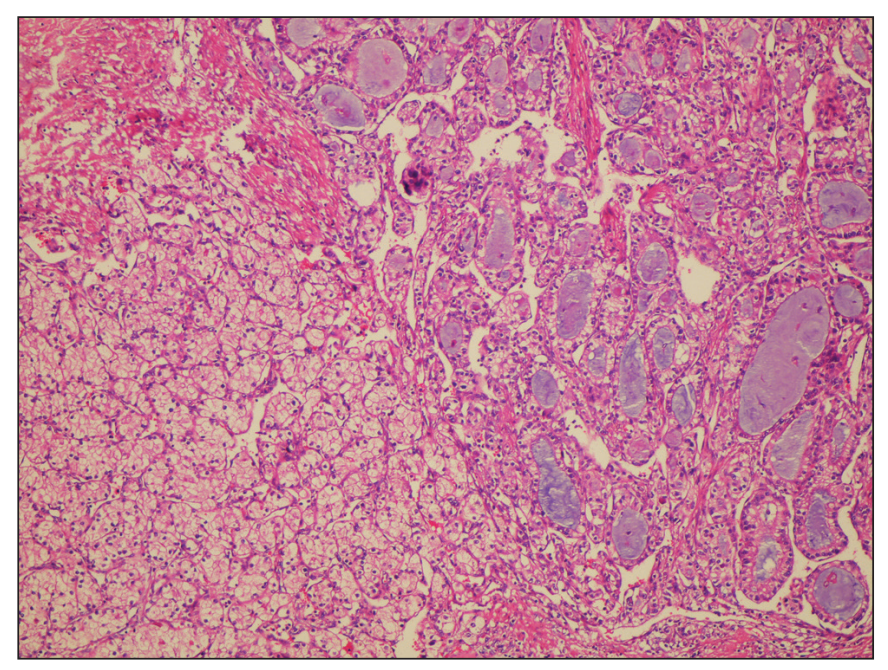

Figure 1: Definite distinction between the areas with a granular cytoplasm and clear cytoplasm (H\&E; x40).

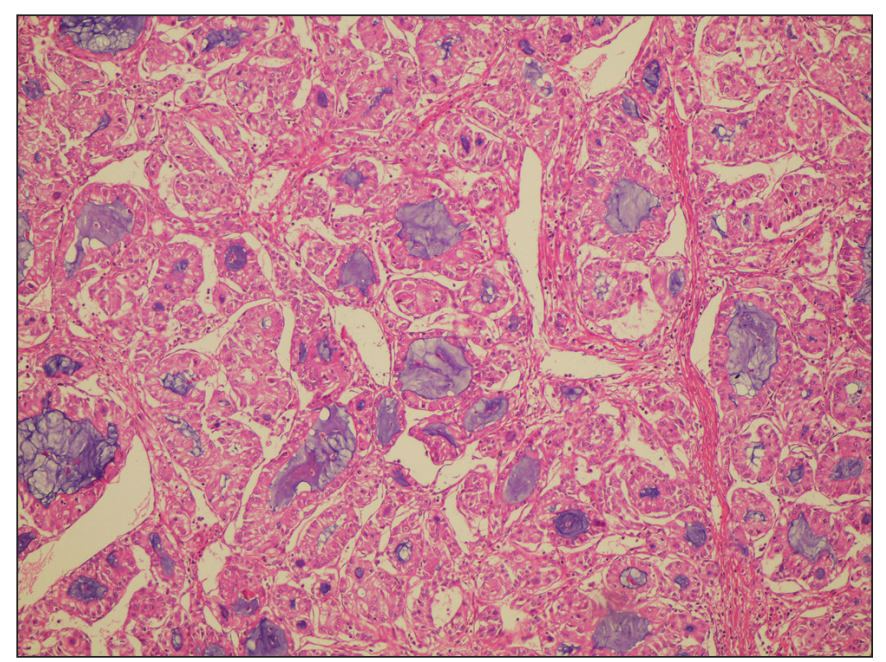

Figure 3: Glandular structures with eosinophilic cytoplasm and high-grade nuclear features, containing mucin in the lumen (H\&E; x100).

\section{DISCUSSION}

The kidney is derived from the mesoderm and intestinal type mucin expression in its carcinomas is an unexpected feature. This is not a commonly expected feature of RCC, the most frequent tumor of the kidney.

The presence of mucin in the tubule in RCC makes diagnosis of the primary tumor more difficult and can create significant problems in metastatic cases. Mucin presence in metastasis is not a feature indicating RCC. Only two cases with intraluminal mucin secretion in clear cell RCC have

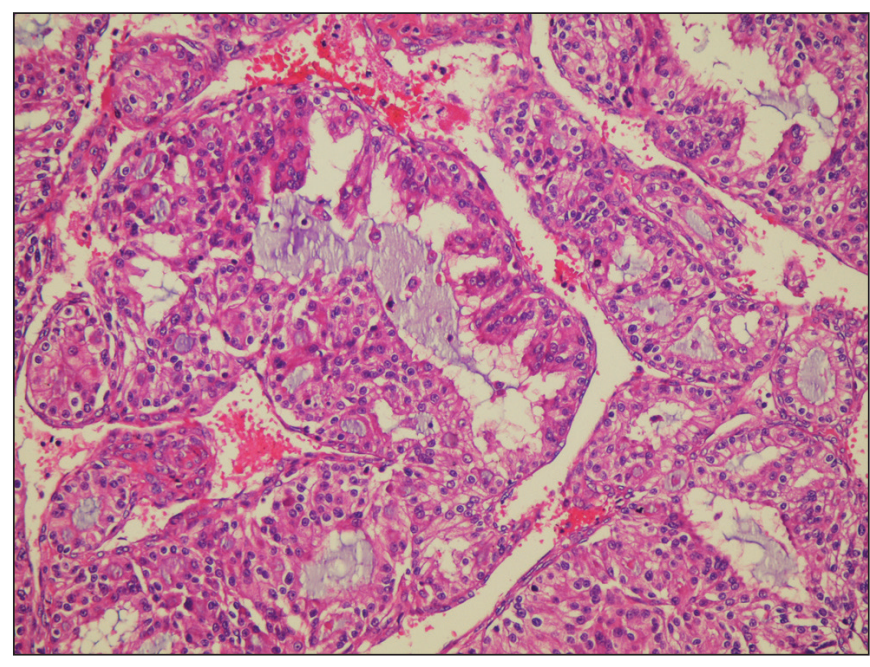

Figure 2: Glandular structures with eosinophilic cytoplasm and high-grade nuclear features, containing mucin in the lumen (H\&E; x200).

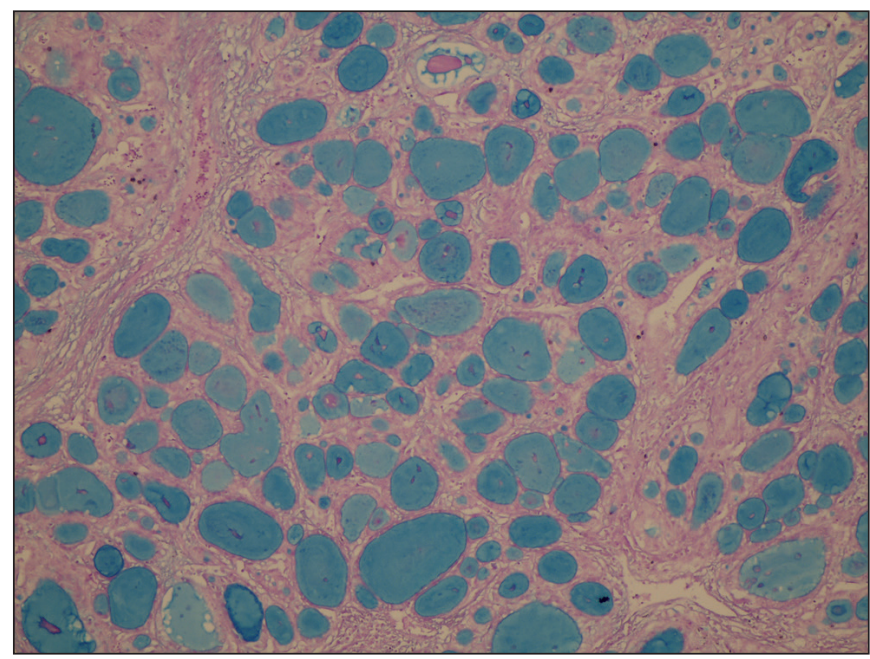

Figure 4: Alcian blue positivity in glandular structures (AlcienBlue; x100). 
been reported so far $(4,5)$. In our case, mucin was present in a primary clear cell RCC; the typical clear cell areas and immunohistochemically diffuse PAX8 and CD10 positivity and CK7 negativity helped in making the diagnosis.

CK20, TTF-1, PSA, GATA-3 can be added to the immune panel in order to distinguish primary renal carcinoma from colonic, pulmonary, prostatic, urothelial carcinoma metastases whenever mucin is seen in the tumor. Although mucin secretion is more frequently seen in mucinous and spindle cell carcinoma, Pivovarcikova et al. reported 7 cases of papillary RCC with extracellular and intracellular mucin secretion (6). Transition of cord-like structures to spindle cells and myxoid stroma in mucinous and spindle cell carcinoma, and presence of papillary structures in papillary RCC are important morphological features for distinction from clear cell RCC with mucin secretion (6). Absence of papillary structures, spindle cells and stromal mucin as well as presence of typical morphological features of clear cell RCC and CK7 negativity aided in the diagnosis. However, cases consisting of cells with complete eosinophilic cytoplasm and containing diffuse mucin may create diagnostic problems. The intraluminal mucin secretion in our case is a quite noteworthy feature of clear cell RCC. Similar histological features were present in two cases published previously $(4,5)$. Our case had similar histology but we also noted areas containing cells with a dense eosinophilic cytoplasm with intraluminal mucin and high nuclear grade with distinct borders. These mucincontaining areas may have developed a different molecular characteristic compared to the clear cell areas. It is interesting that the three cases presented with high nuclear grade (Fuhrman Grade: III) and advanced stage (all pT3) despite the lack of recurrence or metastasis during followup. This indicates the possibility of a high metastasis rate in these cases and the need for more careful clinical follow-up.

In addition to the WHO 2004 classification, the International Society of Urological Pathology (ISUP) has added many new entities to RCC in its Vancouver (2012) meeting $(7,8)$. This new entity was also added in the last WHO classification (9). This new classification includes tubulocystic RCC, RCC related to acquired cystic disease, clear cell (tubulo) papillary RCC, MIT family translocation carcinoma and hereditary leiomyomatosis RCC and related RCC entities in addition to clear cell, papillary and chromophobe RCC. All of these entities have been defined as new entities in the most recent WHO 2016 classification (9). Clear cell RCC with significant mucin secretion has not been considered in the Vancouver consensus meeting and the most recent WHO classification. The presence of very few cases so far may have played a role. This entity will probably continue to be included in the unclassified group for now. New case reports are needed to determine if this entity has any prognostic significance besides the morphological differences.

In conclusion, we believe intraluminal mucin production in renal cell carcinoma is an entity that should be considered despite its rarity. Differentiation of clear cell renal cell carcinoma with mucin secretion from the renal metastasis of mucin-secreting tumors is also important. One must remember that mucin production of the tumor in primary and metastatic foci will not exclude renal cell carcinoma.

\section{CONFLICT OF INTERESTS}

The authors declared no conflict of interest.

\section{REFERENCES}

1. Singh AP, Moniaux N, Chauhan SC, Meza JL, Batra SK. Inhibition of MUC4 expression suppresses pancreatic tumor cell growth and metastasis. Cancer Res. 2004;64: 622-30.

2. Hakomori S. Aberrant glycosylation in tumors and tumorassociated carbohydrate antigens. Adv Cancer Res. 1989;52: 257 331.

3. Niv Y. Mucin and colorectal cancer metastasis. Am J Gaslroenterol. 1994;89:665-9.

4. Val-Bernal JF, Salcedo W, Val D, Parra A, Garijo MF. Mucinsecreting clear cell renal cell carcinoma. A rare variant of conventional renal cell carcinoma. Annal Diagn Pathol. 2013;17: 226-9.

5. Raheem OA, Godebu E, Cohen SA, Shabaik A, Parsons JK. Unclassified mucinous renal cell carcinoma: A rare histopathological entity. Korean J Urol. 2014;55:690-2.

6. Pivovarcikova K, Peckova K, Martinek P, Montiel DP, Kalusova K, Pitra T, Hora M, Skenderi F, Ulamec M, Daum O, Rotterova P, Ondic O, Dubova M, Curik R, Dunatov A, Svoboda T, Michal $\mathrm{M}$, Hes O. Mucin secreting papillary renal cell carcinoma: Clinicopathological, immunohistochemical, and molecular genetic analysis of seven cases. Virchows Arch. 2016; 469: 71-80.

7. Ozagari AA. Recommendations from the 2012 International Society of Urological Pathology Vancouver Consensus Conference on Renal Tumors. Bulletin of Urooncology. 2015;14:285-9.

8. Eble JN, Sauter G, Epstein JI, Sesterhenn IA. Pathology and genetics of the tumours of the urinary system and male genital organs. Lyon: IARC; 2004.

9. Moch H, Humphrey PA, Ulbright TM, Reuter VE. WHO Classification of Tumors of the Urinary System and Male genital organs. Lyon: IARC; 2016. 